\title{
Investigation of rheo-diecasting mold filling of semi-solid A380 aluminum alloy slurry
}

\author{
Zhi-yong Liu ${ }^{1)}$, Wei-min $\mathrm{Mao}^{2)}$, Wei-pan Wang ${ }^{3)}$, Zhi-kai Zheng ${ }^{2)}$, and Rui Yue ${ }^{4)}$ \\ 1) School of Materials Science and Engineering, Tsinghua University, Beijing 100084, China \\ 2) School of Materials Science and Engineering, University of Science and Technology Beijing, Beijing 100083, China \\ 3) Beijing Nanshan Institute of Aeronautical Materials, Beijing 100048, China \\ 4) National Engineering Research Center of Light Alloy Net Forming, Shanghai Jiao Tong University, Shanghai 200240, China \\ (Received: 30 August 2016; revised: 9 January 2017; accepted: 12 January 2017)
}

\begin{abstract}
The rheo-diecasting mold filling capacity and the microstructure of the semi-solid A380 aluminum alloy slurry were investigated. The results show that the mold filling capacity was strengthened with increasing pouring temperature or increasing injection pressure. Under certain process parameters, the mold cavity was fully filled. However, the mold filling capacity decreased with increasing holding time. The mold filling capacity was improved with increasing shape factor of primary $\alpha(\mathrm{Al})$ grains; however, the solid fraction and the grain size significantly increased at the same time. In addition, the microstructures along the route of the spiral samples obviously differed. The grain size decreased gradually from the near-end to the far-end, whereas the shape factor increased gradually.
\end{abstract}

Keywords: aluminum alloys; semi-solid slurry; rheo-diecasting; mold filling; microstructure

\section{Introduction}

During the process of rheo-diecasting mold filling, the semi-solid slurry exhibits thixotropic, pseudo-plastic, and shear-thinning characteristics [1]. In addition, its flow pattern and mold filling capacity strongly influence the surface qualities and mechanical properties of the products. Mold filling is actually influenced by many process parameters, and these process parameters are mutually restricted and interacted [2]. The issue of how to obtain reasonable process parameters for the rheo-diecasting process has been studied by many researchers.

Although in situ X-ray visualization [3-6] and transparent glass slide die films [7-8] have been used by many researchers, alloy experiment and numerical simulation are the two most popular investigative approaches. Bai et al. [9] and Gao et al. [10], through alloy experiments, deduced that a greater punch velocity or injection pressure can impart the semi-solid slurry with better mold filling capacity; they subsequently found through numerical simulation that increasing the size of the inner gate facilitates mold filling [11]. Haga and Fuse [12] adopted different molds and obtained similar results. Using the orthogonal experiment range method, Zhong et al. [13] deduced the rank of the process parameters affecting the mold filling capacity. A step mold has been developed by the Aluminum Association [14]; this mold can reduce the influence of the process parameters on mold filling [15] and reduce their effects during the process of rheo-diecasting mold filling in the absence of turbulent flow [16]. The short-shot process, in conjunction with the formula $L_{\mathrm{N}}=L_{\mathrm{f}} / W\left(L_{\mathrm{N}}\right.$ is the length of the normalized flow interface, $L_{\mathrm{f}}$ is length of the flow front interface, and $W$ is the width of the flow channel), has been used by Janudom et al. [17] to investigate the flow pattern of the semi-solid slurry.

In addition to alloy experiments, numerical simulation is another important method to investigate parameters for the rheo-diecasting process. In numerical simulations, the semi-solid slurry is usually assumed to have constant temperature, pressure, or viscosity. In fact, these parameters 
vary because of heat transfer and the solidification phase transformation, making the simulated results inaccurate [18]. Fortunately, researchers have recognized these problems. Recent numerical simulations have been based on the rheological theory and on the apparent viscosity data recorded in previous experiments [11,19-20]. Nevertheless, semi-solid slurries are still assumed to be incompressible single-phase alloy melts. Although Modigell et al. [21] has predicted solid-liquid segregation through two-phase numerical simulations, they used two relatively independent liquid and solid mathematical models. Thus, numerical simulation methods require further improvement.

The aforementioned studies have been mainly devoted to the mold filling capacity and the flow pattern of the semi-solid slurry, whereas the analysis of the microstructure of the mold filling samples is usually omitted. In this study, the influence of different process parameters on the mold filling capacity, the microstructures of spiral samples under different process parameters, and the variation of the microstructure along the route of the rheo-diecasting mold filling were investigated.

\section{Experimental procedure}

Commercial A380 aluminum alloy with the chemical composition (wt \%) of Si 7.83, $\mathrm{Cu} 3.2, \mathrm{Fe} \leq 0.21, \mathrm{Zn} \leq 0.01$, $\mathrm{Mg} \leq 0.02, \mathrm{Mn} \leq 0.46, \mathrm{~Pb} \leq 0.01$, and $\mathrm{Sn} \leq 0.01$ (balance $\mathrm{Al}$ ) was used. The liquidus and the solidus temperatures of the alloy melt were 525 and $596^{\circ} \mathrm{C}$, respectively, as tested using a differential scanning calorimetry (DSC) method.

The A380 aluminum alloy was melted in the resistance furnace with a graphite clay crucible. The alloy melt was cooled to a fixed pouring temperature and poured into the serpentine channel; after the alloy melt flew through the serpentine channel, it became a semi-solid slurry and was subsequently collected and transferred into the shot sleeve of a horizontal die-casting machine using a preheated preservation scoop. A schematic of the serpentine channel preparation process and the rheo-diecasting mold filling process are shown in Fig. 1. A spiral mold was used, and the scales were designed in the mold cavity (unit scale was $50 \mathrm{~mm}$ ), as shown in Fig. 2. During the rheo-diecasting mold filling, the mold and shot sleeve were preheated to 200 and $350^{\circ} \mathrm{C}$, respectively, and the punch velocity was $0.3 \mathrm{~m} / \mathrm{s}$; under this punch velocity, the semi-solid slurry was pushed into the inner gate of the mold, and the filling velocity in the mold cavity was $11.8 \mathrm{~m} / \mathrm{s}$. The process parameters of the rheo-diecasting mold filling are shown in Table 1.

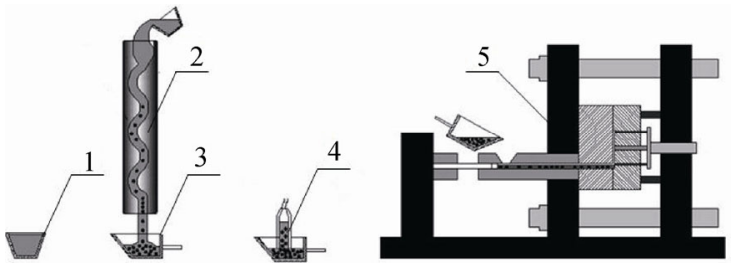

Fig. 1. Schematics of the semi-solid slurry preparation and rheo-diecasting processes. 1 - Graphite clay melting crucible; 2 - Serpentine channel; 3 - Heat preservation scoop; 4 Vacuum intake device; 5 - Horizontal die casting machine.

The microstructures of spiral samples were observed using a Neuphoto21 optical microscope, and the Image-Pro Plus analysis software was used to calculate the average grain diameter and the shape factor of the primary $\alpha(\mathrm{Al})$ grains by applying Eqs. (1) and (2), respectively:

$$
\begin{aligned}
& D=\sum_{i=1}^{N} \sqrt{4 A / \pi} / N \\
& F=\sum_{i=1}^{N}\left(4 \pi A / P^{2}\right) / N
\end{aligned}
$$

where $D, F_{\mathrm{s}}, A, N$, and $P$ are the average diameter, shape factor, area, number, and perimeter of the primary $\alpha(\mathrm{Al})$ grains, respectively, and $F_{\mathrm{s}}$ is a value close to 1 , corresponding to better globularity of the primary $\alpha(\mathrm{Al})$ grains. The distribution of elements in the spiral samples was observed using a ZEISS SUPRA40 scanning electron microscope.

\begin{tabular}{|c|c|c|c|c|c|c|c|}
\hline \multirow{2}{*}{ Sample } & \multicolumn{3}{|c|}{ Process parameter } & \multirow{2}{*}{ Sample } & \multicolumn{3}{|c|}{ Process parameter } \\
\hline & $T^{*} /{ }^{\circ} \mathrm{C}$ & $P^{\#} / \mathrm{MPa}$ & $t^{\&} / \mathrm{s}$ & & $T^{*} /{ }^{\circ} \mathrm{C}$ & $P^{\#} / \mathrm{MPa}$ & $t^{\&} / \mathrm{s}$ \\
\hline A & 610 & 70 & 0 & $\mathrm{~F}$ & 650 & 35 & 0 \\
\hline $\mathrm{B}$ & 630 & 70 & 0 & G & 650 & 105 & 0 \\
\hline $\mathrm{C}$ & 650 & 70 & 0 & $\mathrm{H}$ & 670 & 70 & 30 \\
\hline $\mathrm{D}$ & 670 & 70 & 0 & I & 670 & 70 & 60 \\
\hline $\mathrm{E}$ & 650 & 15 & 0 & & & & \\
\hline
\end{tabular}

Table 1. Process parameters of rheo-diecasting mold filling

Note: $T^{*}$ - pouring temperature; $P^{\#}-$ injection pressure; $t^{\&}$ - holding time. 


\section{Results and discussion}

\subsection{Mold filling capacity of the rheo-diecasting}

Figs. 2(a)-2(d) show four samples produced at pouring temperatures of $610,630,650$, and $670^{\circ} \mathrm{C}$, respectively; their corresponding lengths are approximately 695, 790, 875 , and $1030 \mathrm{~mm}$, respectively. These results indicate that the length of the spiral sample increases with increasing pouring temperature. As shown in Fig. 3(a), when the pouring temperature is less than $650^{\circ} \mathrm{C}$, the relationship between the length of the spiral samples and the pouring temperature is approximately linear. However, when the pouring temperature is increased to $670^{\circ} \mathrm{C}$, the length of the spiral sample is increased sharply. This phenomenon may be related to the solid fraction and the apparent viscosity of the semi-solid slurry. When the pouring temperature is decreased, increases in the solid fraction and the apparent viscosity of the semi-solid slurry are inevitable. However, during mold filling, the higher the solid fraction of the semi-solid slurry, the more primary $\alpha(\mathrm{Al})$ grains gathering at the inner gate of the mold cavity, which reduces the size of the inner gate. Thus, the time of mold filling is prolonged and the heat loss of the semi-solid slurry is increased, decreasing the flow capacity of the semi-solid slurry and the mold filling capacity of the semi-solid slurry. However, the semi-solid slurry with a higher solid fraction has a higher apparent viscosity, increasing the friction force between the mold cavity and the semi-solid slurry and eventually decreasing the mold filling capacity. Thus, the length of the spiral sample changes as the pouring temperature varies, and a stronger mold filling capacity corresponds to a higher pouring temperature, and vice versa.

As shown in Figs. 2(e)-2(g), the spiral samples were produced under different injection pressures of 15, 35, 70, and $105 \mathrm{MPa}$, and their corresponding lengths are approximately 500, 685, 875, and $1205 \mathrm{~mm}$, respectively. As shown in Fig. 3(b), the length of the spiral sample increases with increasing injection pressure; when the injection pressure is increased from 70 to $105 \mathrm{MPa}$, the length of the spiral sample is increased sharply and the mold cavity is filled fully. Under the condition that the resistance of mold filling is constant, the effective mold filling power increases and the punch velocity and the mold filling capacity are also enhanced as the injection pressure is strengthened; thus, the time of mold filling is shortened and the heat loss of the semi-solid slurry is decreased. At the same time, because the semi-solid slurry exhibits pseudo-plastic behavior, its apparent viscosity decreases with increasing shear rate $(\tau=\eta D$, where $\tau, \eta$, and $D$ are the shear stress, apparent viscosity, and shear rate, respectively [22]). On the basis of the aforementioned considerations, the apparent viscosity of the semi-solid slurry and the viscous friction between semi-solid slurry and the mold cavity can be reduced by increasing the injection pressure. We concluded that the length of the spiral sample can be extended with an increase in injection pressure. However, when the injection pressure is too high, the spiral sample will become several fragments because the semi-solid slurry is dispersed.

The mold filling capacity of the semi-solid slurry is not only related to the solid fraction but also to the morphology of primary $\alpha(\mathrm{Al})$ grains [2]. Thus, we held the semi-solid slurry for 0,30 , and $60 \mathrm{~s}$ to investigate the influence of the morphology of primary $\alpha(\mathrm{Al})$ grains on the rheo-diecasting mold filling capacity of the semi-solid slurry. Figs. 2(d), 2(h), and 2(i) show three spiral samples whose semi-solid slurry was held for 0,30 , and $60 \mathrm{~s}$, respectively, before rheo-diecasting mold filling. As shown in Fig. 3(c), the length of the spiral samples decreases with increasing holding time. When the holding time is prolonged from 0 to $30 \mathrm{~s}$, the length of the spiral sample is sharply reduced from 1030 to $740 \mathrm{~mm}$. When the holding time is further prolonged from 30 to $60 \mathrm{~s}$, the length of the spiral sample is shortened from 740 to $655 \mathrm{~mm}$, which is relatively slight. We concluded that the mold filling capacity of the semi-solid slurry decreases rapidly at the early stage of holding but changes are not obvious at the later stage of holding. We therefore inferred that the holding of the semi-solid slurry is not conducive to mold filling at the early stage of holding. However, the later stage of holding is different from the earlier stage; the mold filling capacity is weakened slightly. Obviously, the solid fraction, the average grain diameter, and the shape factor of the primary $\alpha(\mathrm{Al})$ grains will be increased, enlarged, and improved with increasing holding time, respectively. Without doubt, the first two parameters decrease the mold filling capacity and the last parameter enhances the mold filling capacity. During mold filling, the influence of the first two parameters on the mold filling capacity will be canceled out by the last parameter. At the early stage of holding, the first two parameters obviously increase, but the last parameter improves only slightly; thus, the mold filling capacity is weakened substantially. However, at the later stage of holding, the last parameter is sufficiently improved, whereas the first two parameters increase only slightly; thus, the mold filling capacity is weakened slightly. 

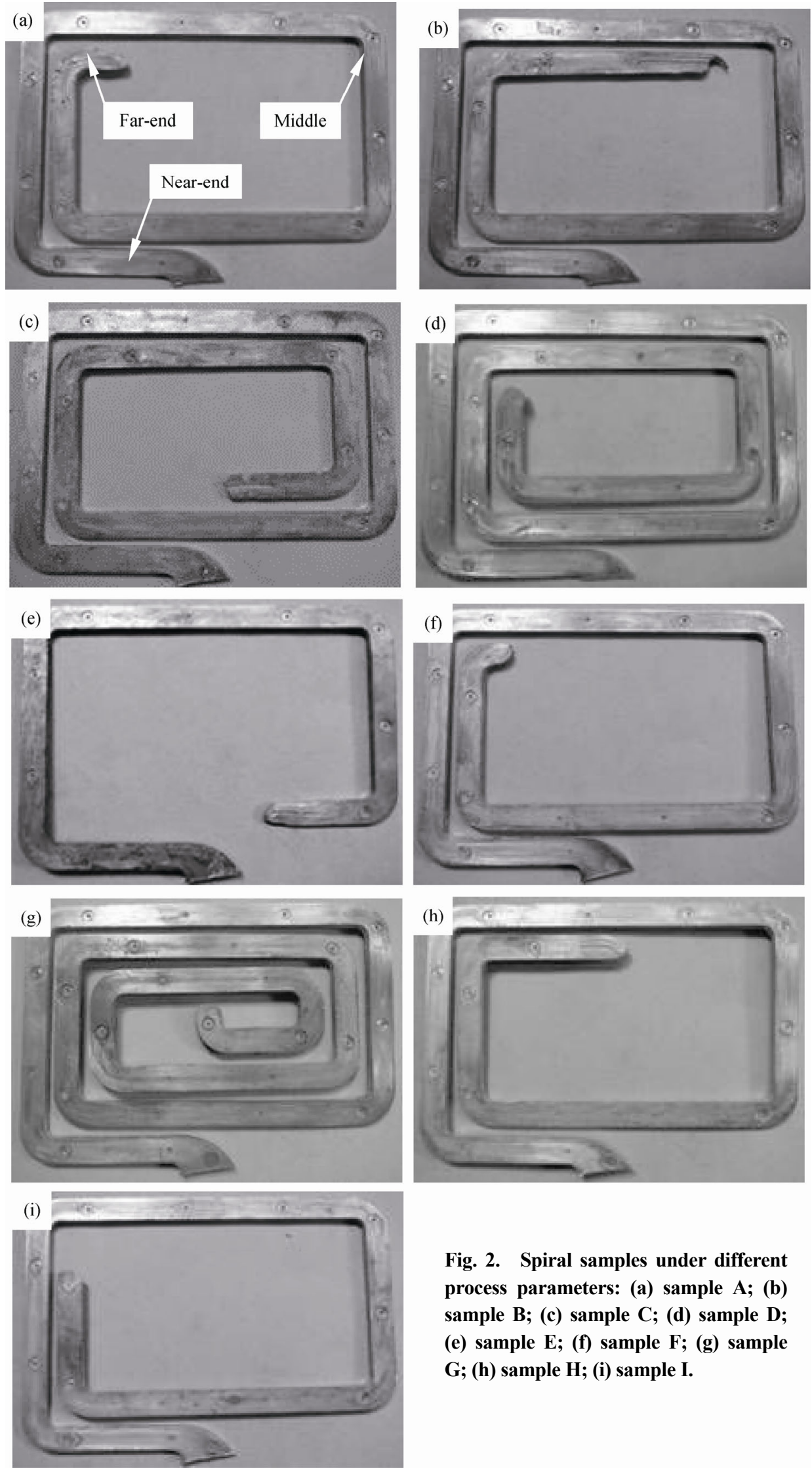

Fig. 2. Spiral samples under different process parameters: (a) sample $A$; (b) sample B; (c) sample C; (d) sample D; (e) sample E; (f) sample F; (g) sample G; (h) sample H; (i) sample I. 


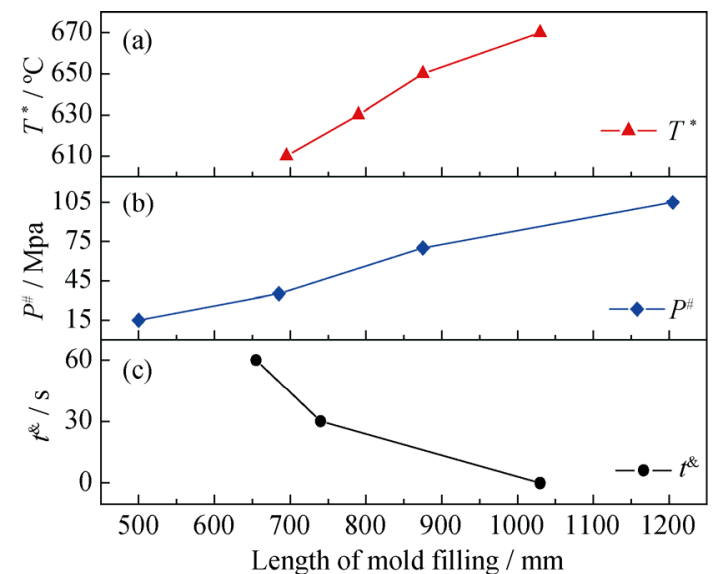

Fig. 3. Curves of the lengths of samples vs. different process parameters.

\subsection{Microstructures of the spiral samples}

To further understand and explain the influence of different process parameters on the mold filling capacity, the microstructures at the middle of the spiral samples under different process parameters are observed.

Figs. 4 (a) 4 (d) show the microstructures of the spiral samples under different pouring temperatures of 610,630 , 650 , and $670^{\circ} \mathrm{C}$, and their corresponding average grain diameters are about 18, 20, 22, and $25 \mu \mathrm{m}$, respectively, and their shape factors are $0.84,0.81,0.79$, and 0.78 , respectively. This rule agree with the results in reference [23]; that is, most microstructures of the semi-solid slurry can be retained under a certain injection pressure, the average grain diameter is increased, and the shape factor is decreased with increasing pouring temperature; however, compared with the results reported in reference [23], the average grain diameters of the spiral samples are smaller and the shape factors are higher, which may be related to the rapid solidification and to frequent impact and friction among the primary $\alpha(\mathrm{Al})$ grains during mold filling. In addition, the solid fraction of primary $\alpha(\mathrm{Al})$ grains is decreased and the number of secondary $\alpha_{2}(\mathrm{Al})$ grains is increased per unit area with increasing pouring temperature, especially when the pouring temperature is greater than $630^{\circ} \mathrm{C}$, as shown in Figs. 4(c) and 4(d). During mold filling, a higher pouring temperature results in a lower solid fraction of primary $\alpha(\mathrm{Al})$ grains in the semi-solid slurry; as a result, the mold filling resistance created by the primary $\alpha(\mathrm{Al})$ grains is lower. When the pouring temperature is too high, the viscosity of the semi-solid slurry will be approximately equal to that of the liquid melt; a higher pouring temperature results in a greater mold filling capacity, though, the filling is instability.

Figs. $4(\mathrm{e})-4(\mathrm{~g})$ show the microstructures of the spiral samples under different injection pressures $(15,35,70$, and
$105 \mathrm{MPa}$ ); their corresponding average grain diameters are $28,24,22$, and $16 \mu \mathrm{m}$, respectively, and their shape factors are $0.69,0.74,0.79$, and 0.83 , respectively. That is, the average grain diameter decreases and the shape factor increases with increasing injection pressure. At the same time, the number of the secondary $\alpha_{2}(\mathrm{Al})$ grains is increased per unit area. In particular, when the injection pressure is $105 \mathrm{MPa}$, the number of primary $\alpha(\mathrm{Al})$ grains and the number of secondary $\alpha_{2}(\mathrm{Al})$ grains are equivalent, as shown in Fig. $4(\mathrm{~g})$. During mold filling, the injection pressure has an important influence on the interfacial heat transfer, the solidification of semi-solid slurry, and the melting point of the alloy as well as the critical energy of nucleation. When the injection pressure is greater than $70 \mathrm{MPa}$, it will easily deform the solidified shell and reduce the gap formed because of the solidification shrinkage of the alloy, resulting in the interfacial heat transfer coefficient increasing with increasing cooling rate. Eq. (3) can be used to describe the effect of the injection pressure on the melting point of the alloy [24]:

$\frac{\mathrm{d} T_{\mathrm{p}}}{\mathrm{d} P}=\frac{T_{\mathrm{m}}\left(V_{1}-V_{\mathrm{s}}\right)}{L_{\mathrm{m}}}$

where $T_{\mathrm{m}}$ is the melting point of the alloy under normal pressure; $\mathrm{d} T_{\mathrm{p}}$ is the change of melting point under injection pressure; $V_{1}$ and $V_{\mathrm{s}}$ are the molar volumes of the alloy liquid and the solid phase; respectively; $L_{\mathrm{m}}$ is the latent heat of crystallization.

Eq. (3) indicates that the melting point of the alloy is improved when the injection pressure is increased, which means that the corresponding supercooling degree is improved; thus, its critical radius is decreased when the residual liquid of the semi-solid slurry solidifies under pressure. Its critical radius can be described as Eq. (4) [25]:

$r_{\mathrm{c}}=\frac{2 \sigma_{\mathrm{ls}} T_{0}}{L_{\mathrm{m}} \Delta T+K \varepsilon T_{0} P}$

where $r_{\mathrm{c}}$ is the critical radius; $\sigma_{\mathrm{ls}}$ is the solid-liquid interfacial tension; $T_{0}$ is the melting point of the alloy under normal pressure; $L_{\mathrm{m}}$ is the latent heat of crystallization under injection pressure; $\Delta T$ is the supercooling degree under injection pressure; $K$ is a constant; $\varepsilon$ is the volume shrinkage; and $P$ is the injection pressure.

Moreover, the enhancement of the injection pressure can improve the effective mold filling power, reduce the influence of the mold filling resistance, and shorten the mold filling time. As a consequence, the impact and the friction among the primary $\alpha(\mathrm{Al})$ grains are more energetic and more frequent, respectively, and the primary $\alpha(\mathrm{Al})$ grains are refined and spheroidized; the residual liquid of the semi-solid slurry rapidly solidifies and forms the secondary 

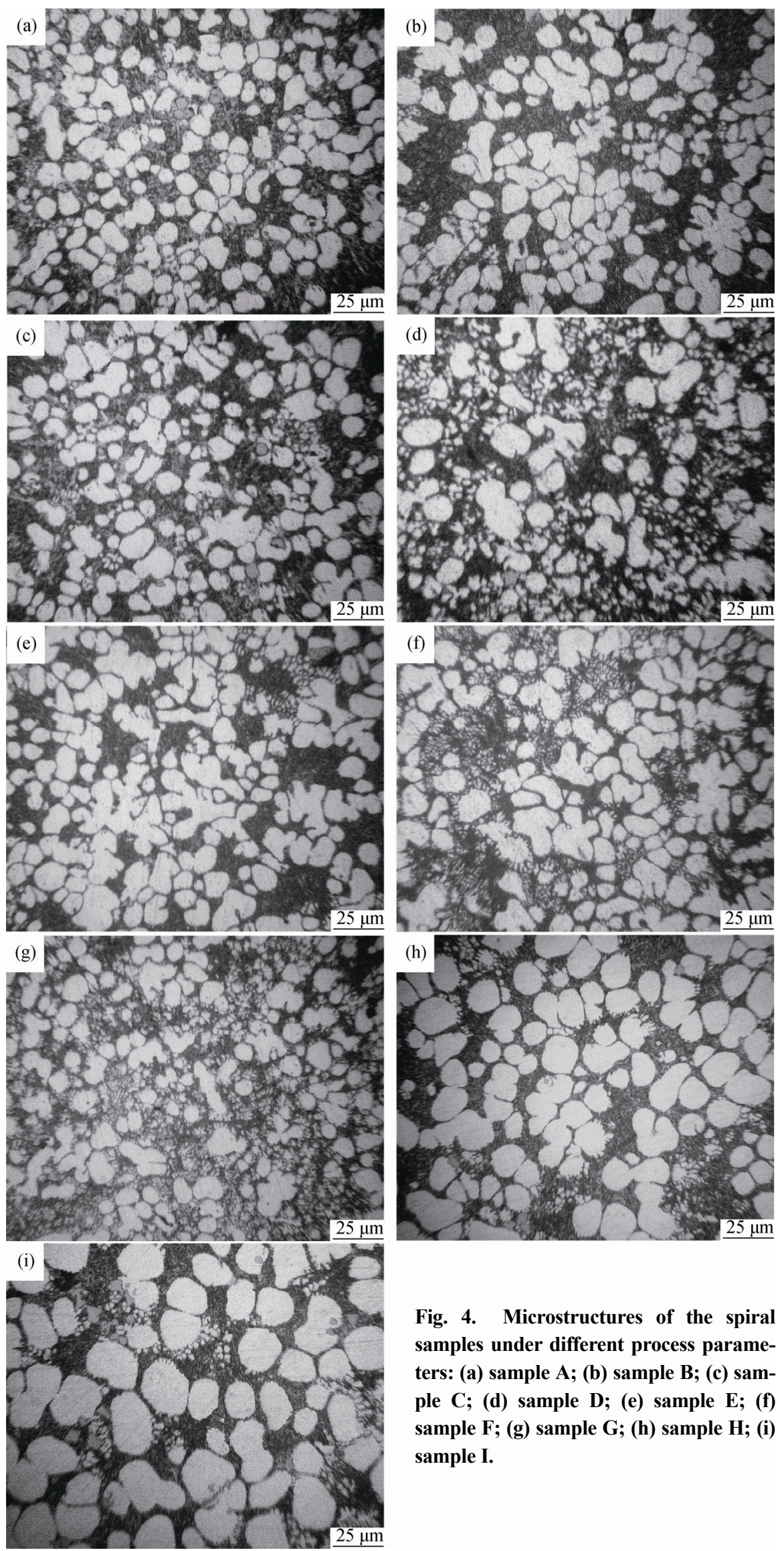

Fig. 4. Microstructures of the spiral samples under different process parameters: (a) sample A; (b) sample B; (c) sample $C$; (d) sample $D$; (e) sample $E$; (f) sample F; (g) sample $G$; (h) sample $H$; (i) sample I. 
$\alpha_{2}(\mathrm{Al})$ grains. The relation between the grain diameter and the cooling rate can be described by $d=B T^{m}$, where $d$ is the grain diameter, $T$ is the supercooling degree, and $B$ and $m$ are constants [26].

Figs. 4(d), 4(h), and 4(i) show the microstructures of spiral samples under different holding times $(0,30$, and $60 \mathrm{~s})$; their corresponding average grain diameters are 25,32 , and $36 \mu \mathrm{m}$, respectively, and their shape factors are $0.78,0.81$, and 0.87 , respectively. Both the average grain diameter and the shape factor increase with increasing holding time, consistent with the Ostwald ripening mechanism [27]. In addition, when the holding time is prolonged from 0 to $30 \mathrm{~s}$, the average diameter and the solid fraction of the primary $\alpha(\mathrm{Al})$ grains are increased dramatically, whereas the shape factor of the primary $\alpha(\mathrm{Al})$ grains is improved only slightly. However, when the holding time is prolonged from 30 to $60 \mathrm{~s}$, the average diameter and the solid fraction of the primary $\alpha(\mathrm{Al})$ grains are increased slightly, whereas the shape factor of the primary $\alpha(\mathrm{Al})$ grains is improved substantially. On the basis of the mold filling results, we inferred that, when the semi-solid slurry has a higher solid fraction and a larger average grain diameter, the mold filling capacity can likely be decreased. However, the mold filling capacity can undoubtedly be improved when the primary $\alpha(\mathrm{Al})$ grains have a larger shape factor.

\subsection{Microstructure of the route of mold filling}

Under different process parameters, the variation of the microstructures along the route of mold filling has similar rules. With sample D taken as an example, Figs. 5(a) and 5(b) show the microstructures of the center and edge in the near-end, respectively. The primary $\alpha(\mathrm{Al})$ grains mainly consist of grains with rosette-like, near-spherical-like, and a small number of dendritic-like shapes, where the average grain diameter and shape factor of the primary $\alpha(\mathrm{Al})$ grains are $28 \mu \mathrm{m}$ and 0.67 , respectively. Figs. 5(c) and 5(d) show the microstructures of the center and the edge in the middle, respectively. The primary $\alpha(\mathrm{Al})$ grains mainly display the morphology of the grains with spherical-like and rosette-like shapes, where the average grain diameter and the shape factor of the primary $\alpha(\mathrm{Al})$ grains are $20 \mu \mathrm{m}$ and 0.73 , respectively. Compared with the near-end, both the number of primary $\alpha(\mathrm{Al})$ grains per unit area and the solid fraction of the primary $\alpha(\mathrm{Al})$ grains are lower in the middle. The number of primary $\alpha(\mathrm{Al})$ grains per unit area decreases from 1050 to $940 \mathrm{~mm}^{-2}$, and the solid fraction decreases from $87 \%$ to $82 \%$; however, the shape factor is improved from 0.67 to 0.73 . Figs. $5(\mathrm{e})$ and $5(\mathrm{f})$ show the microstructures of the center and the edge in the far-end, respectively. Compared with the middle position, the microstructure of the far-end differs substantially. Both the number and solid fraction of the primary $\alpha(\mathrm{Al})$ grains per unit area decrease: the number of primary $\alpha(\mathrm{Al})$ grains per unit area decreases from 940 to $760 \mathrm{~mm}^{-2}$, and the solid fraction decreased from $82 \%$ to $69 \%$. However, the shape factor of the primary $\alpha(\mathrm{Al})$ grains is obviously improved from 0.73 to 0.81 . This phenomenon is likely related to aggregation of the primary $\alpha(\mathrm{Al})$ grains at the inner gate and to pressure shearing. However, the aggregation of the primary $\alpha(\mathrm{Al})$ grains at the inner gate increases the mold filling resistance for the subsequent semi-solid slurry; thus, the number of primary $\alpha(\mathrm{Al})$ grains per unit area and the solid fraction both decrease. By contrast, large primary $\alpha(\mathrm{Al})$ grains are sheared and broken under the pressure shearing; at the same time, mutual impact and friction among primary $\alpha(\mathrm{Al})$ grains occur during mold filling, resulting in the primary $\alpha(\mathrm{Al})$ grains getting refined and spheroidized [28].

In addition to what has already been mentioned, obvious solid-liquid segregation bands are observed at the edge of the near-end and the middle, as shown with the line in Figs. 5(b) and 5(d). This phenomenon may be related to the order of solidification. The mold cavity is filled in the form of residual liquid encapsulating primary $\alpha(\mathrm{Al})$ grains; as a result, the residual liquid of the semi-solid slurry contacts the inner wall of the mold cavity before contacting the primary $\alpha(\mathrm{Al})$ grains because of its own free characteristics. As a result, it rapidly solidifies and forms the surface of the spiral sample. Meanwhile, the other residual liquid feeds the solidification shrinkage and further accumulates in this region under pressure, which impedes the local heat transfer. Thus, the solidification of this region and the center may be simultaneous. To confirm the relationship between solid-liquid segregation band and the solidification sequence, we investigated the phase compositions and the element area distributions of the sample by SEM and energy-dispersive X-ray spectroscopy (EDS). As shown in Fig. 6, at the edge of the sample, the elemental composition consists almost entirely of elements $\mathrm{Al}$ and $\mathrm{Si}$, with a trace amount of $\mathrm{Cu}$. However, near the edge of the sample, elements $\mathrm{Al}, \mathrm{Si}$, and $\mathrm{Cu}$ are present; moreover, the proportion of the $\mathrm{Cu}$ is quite high, as shown with the red rectangle in Fig. 6. The proportion of $\mathrm{Cu}$ decreases near the center of the sample. A previous investigation indicated that $\mathrm{CuAl}_{2}$ precipitates at the end stage of solidification [29]. We therefore inferred that a portion of the primary $\alpha(\mathrm{Al})$ grains and the residual liquid form the edge of the sample; moreover, the residual liquid forms primary $\alpha_{2}(\mathrm{Al})$ grains and $\mathrm{Al}-\mathrm{Si}$ eutectic. Because heat transfer at the edge is quick, the residual liquid mainly forms the primary $\alpha_{2}(\mathrm{Al})$ grains. The residual liquid accumulates 

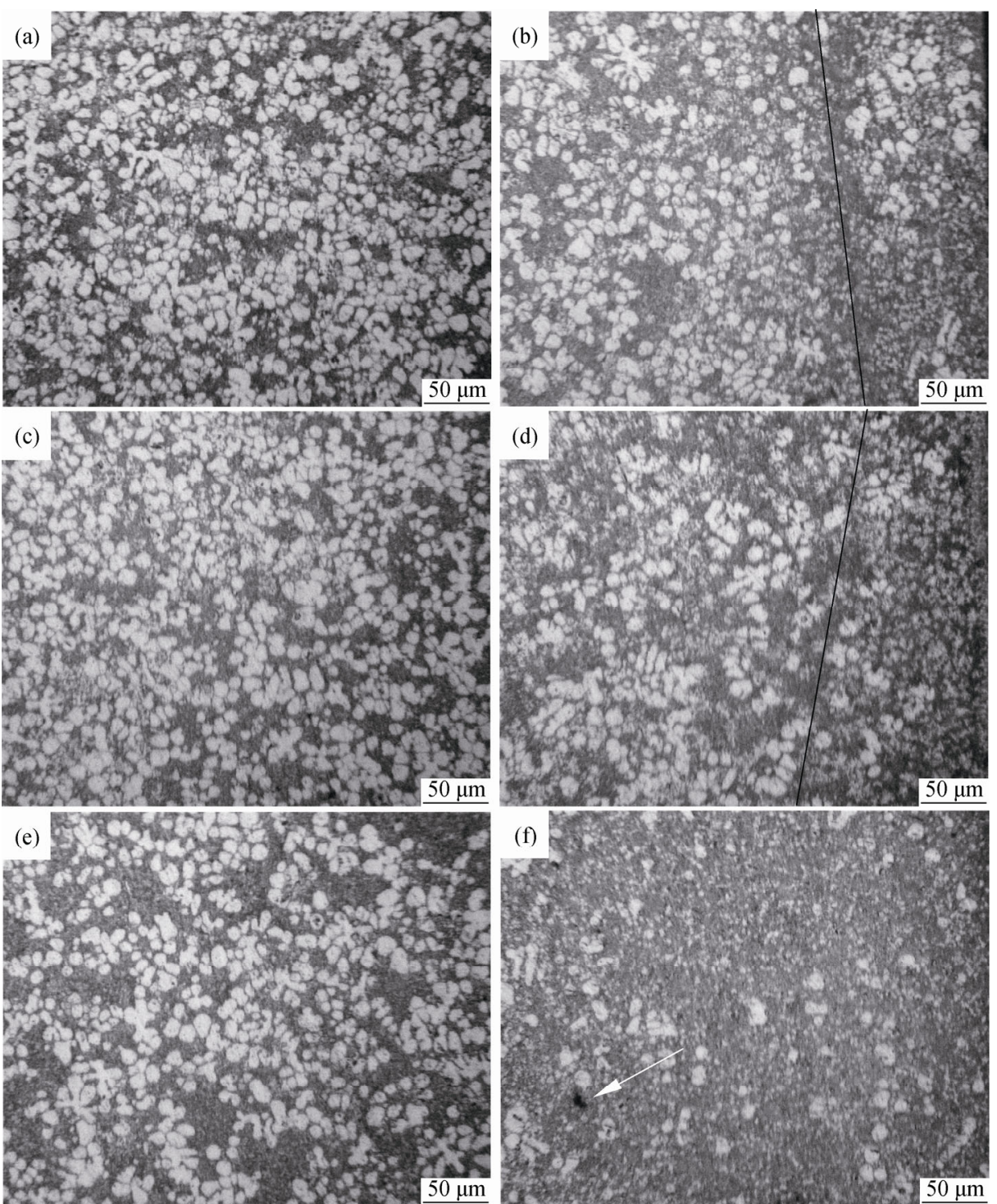

Fig. 5. Microstructures in the near-end and middle position of sample D: (a) center of the near-end; (b) edge of the near-end; (c) center of the middle; (d) edge of the middle; (e) center of the far-end; (f) edge of the far-end.
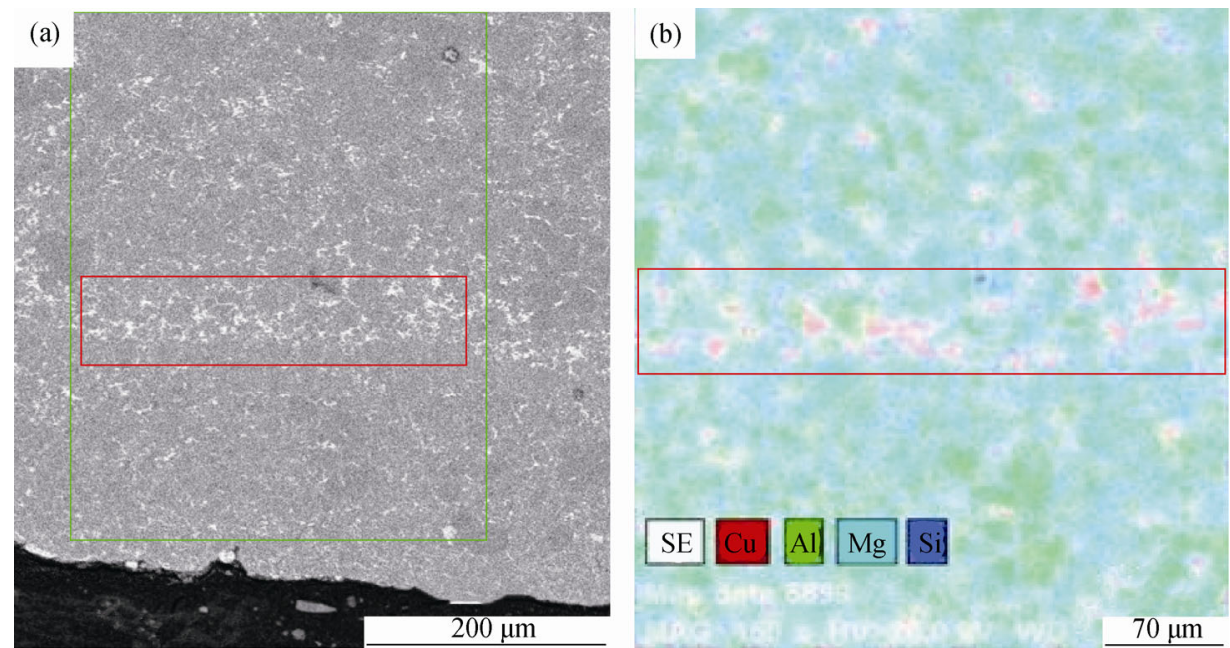

Fig. 6. Distribution of elements in the spiral sample: (a) scanning electron microscopy image; (b) energy-dispersive X-ray spectroscopy mapping image. 
under the pressure near the edge of the sample, forming primary $\alpha_{2}(\mathrm{Al})$ grains, $\mathrm{Al}-\mathrm{Si}$ eutectic, and $\mathrm{CuAl}_{2}$ precipitates. Because of the difficulty of heat transfer in this region and the accumulation of the residual liquid, the residual liquid mainly forms $\mathrm{CuAl}_{2}$ precipitates and $\mathrm{Al}-\mathrm{Si}$ eutectic; thus, the solid-liquid segregation bands form in this region. Difficulty of heat transfer also occurs in the center; however, the proportion of the residual liquid is smaller and the residual liquid mainly forms $\mathrm{Al}-\mathrm{Si}$ eutectic; thus, no solid-liquid segregation occurs. When the proportion of the residual liquid is too high, the solid-liquid segregation will change from bands to a region; shrinkage may occur and pores may form, as shown in Fig. 5(f).

\section{Conclusions}

(1) The mold filling capacity of semi-solid A380 aluminum alloy is strengthened with increasing pouring temperature or with increasing injection pressure, and the injection pressure strongly influences mold filling. The mold cavity is fully filled when the pouring temperature is $650^{\circ} \mathrm{C}$, the mold temperature is approximately $200^{\circ} \mathrm{C}$, the injection pressure is $105 \mathrm{MPa}$, and the holding time is $0 \mathrm{~s}$.

(2) The mold filling capacity decreases with increasing holding time. When the holding time is prolonged from 0 to $30 \mathrm{~s}$, the mold filling capacity decreases sharply, and when the holding time is prolonged from 30 to $60 \mathrm{~s}$, the mold filling capacity decreases gently. Although the shape factor of the primary $\alpha(\mathrm{Al})$ grains is beneficial to mold filling, the average grain diameter of the primary $\alpha(\mathrm{Al})$ grains and the solid fraction weaken the mold filling capacity of the semi-solid slurry.

(3) Obvious differences exist between the microstructure along the route of the spiral samples and the microstructure of the cross section; the average grain diameter of the primary $\alpha(\mathrm{Al})$ grains decreases gradually from the near-end to the far-end, but the shape factor increases gradually. The primary $\alpha(\mathrm{Al})$ grains evenly distribute in the center area; however, they unevenly distribute in the edge area, corresponding to the solid-liquid segregation band at the edge of the spiral sample.

Open Access This article is distributed under the terms of the Creative Commons Attribution 4.0 International License (http://creativecommons.org/licenses/by/4.0/), which permits unrestricted use, distribution, and reproduction in any medium, provided you give appropriate credit to the original author(s) and the source, provide a link to the Creative Commons license, and indicate if changes were made.

\section{Acknowledgements}

This work was financially supported by the National Basic Research Program of China (No. 2011CB606300) and the National Natural Science Foundation of China (No. 5077400). The authors would also like to express their appreciation to the Analytical and Testing Center of USTB.

\section{References}

[1] M.C. Flemings, Behavior of metal alloys in the semisolid state, Metall. Trans. B, 22(1991), No. 3, p. 272.

[2] W.M. Mao, Semisolid Metal Forming Technology, China Machine Press, Beijing, 2004, p. 62.

[3] M. Sistaninia, S. Terzi, A.B. Phillion, J.M. Drezet, and M. Rappaz, 3-D granular modeling and in situ X-ray tomographic imaging: A comparative study of hot tearing formation and semi-solid deformation in $\mathrm{Al}-\mathrm{Cu}$ alloys, Acta Mater., 61(2013), No. 10, p. 3831.

[4] A.B. Phillion, R.W. Hamilton, D. Fuloria, A.C.L. Leung, P. Rockett, T. Connolley, and P.D. Lee, In situ X-ray observation of semi-solid deformation and failure in $\mathrm{Al}-\mathrm{Cu}$ alloys, Acta Mater., 59(2011), No. 4, p. 1436.

[5] H.D. Zhao, I. Ohnaka, and J.D. Zhu, Modeling of mold filling of Al gravity casting and validation with X-ray in-situ observation, Appl. Math. Modell., 32(2008), No. 2, p. 185.

[6] S. Zabler, A. Ershov, A. Rack, F. Garcia-Moreno, T. Baumbach, and J. Banhart, Particle and liquid motion in semi-solid aluminum alloys: A quantitative in situ microradioscopy study, Acta Mater., 61(2013), No. 4, p. 1244.

[7] A. Neag, V. Favier, R. Bigot, and H.V. Atkinson, Analysis by micromechanical modeling on material flow under rapid compression in the semi-solid state, Solid State Phenom., 217-218(2014), p. 182.

[8] M. Hufschmidt, M. Modigell, and J. Petera, Modelling and simulation of forming processes of metallic suspensions under non-isothermal conditions, J. Non-Newtonian Fluid Mech., 134(2006), No. 1-3, p. 16.

[9] Y.L. Bai, W.M. Mao, S.F. Gao, and Q. Li, Effect of technological parameters on filling behavior of semi-solid A356 alloy by rheocasting, J. Univ. Sci. Technol. Beijing, 28(2006), No. 7, p. 645.

[10] S.F. Gao, W.M. Mao, Y.L. Bai, and Q. Li, Filling ability of semi-solid A356 alloy in rheo-casting and microstructure distribution, Spec. Cast. Nonferrous Alloys, 25(2005), No. 10, p. 598.

[11] Y.L. Bai, W.M. Mao, H. Xu, H. Hou, and J. Xu, Numerical simulation on rheo-diecasting mould filling of semi-solid key-shaped component, Trans. Nonferrous Met. Soc. China, 18(2008), No. 3, p. 682.

[12] T. Haga and H. Fuse, Semi-solid die casting of Al-25\% Solid State Phenom., 217-218(2014), p. 312

[13] G. Zhong, S.S. Wu, L. Wan, and B. Qin, Study on filling capacity of semi-solid $\mathrm{Al}-20 \% \mathrm{Si}$ alloy prepared by rheo-casting, Foundry, 59(2010), No. 10, p. 1044. 
[14] G. Timelli, S. Capuzzi, and F. Bonollo, Optimization of a permanent step mold design for $\mathrm{Mg}$ alloy castings, Metall. Mater. Trans. B, 46(2015), No. 1, p. 473.

[15] X.J. Yang, Study on the Rheological Behavior and Gates of the Thixoforming of Semi-Solid Aluminum (A356) Alloy [Dissertation], Shanghai University, Shanghai, 1999, p. 66.

[16] P.F. Feng, J.L. Tang, S.S. Li, and D.B. Zeng, Experimental studies on rheocasting processing of A356 alloy, Foundry, 56(2007), No. 1, p. 31.

[17] S. Janudom, J. Wannasin, J. Basem, and S. Wisutmethangoon, Characterization of flow behavior of semi-solid slurries containing low solid fractions in high-pressure die casting, Acta Mater., 61(2013), No. 16, p. 6267.

[18] N. Pathak, A. Kumar, A. Yadav, and P. Dutta, Effects of mould filling on evolution of the solid-liquid interface during solidification, Appl. Therm. Eng., 29(2009), No. 17-18, p. 3669.

[19] C.G. Kang and J.W. Bae, Numerical simulation of mold filling and deformation behavior in rheology forming process, Int. J. Mech. Sci., 50(2008), No. 5, p. 944.

[20] J.L. Ren, J. Ouyang, and T. Jiang, An improved particle method for simulation of the non-isothermal viscoelastic fluid mold filling process, Int. J. Heat Mass Transfer, 85(2015), p. 543.

[21] M. Modigell, M. Hufschmidt, and J. Petera, Two phase simulation and visualisation of isothermal die filling processes, [in] The 7th International Conference on Semi-Solid Processing of Alloys and Composites, Tsukuba, 2002, p. 509
[22] A.N. Alexandrou, G.C. Florides, and G.C. Georgiou, Squeeze flow of semi-solid slurries, J. Non-Newtonian Fluid Mech., 193(2013), p. 103.

[23] Z.Y. Liu, M.W. Mao, W.P. Wang, and Z.K. Zheng, Preparation of semi-solid A380 aluminum alloy slurry by serpentine channel, Trans. Nonferrous Met. Soc. China, 25(2015), No. 5, p. 1426.

[24] S.J. Luo, B.G. Chen, and P.X. Qi, Hydraulic Die Forging and Squeeze Casting Technology, Chemical Industry Press, Beijing, 2007, p. 34.

[25] Z.Z. Chen, Preparation of Semi-Solid Slurry Through The Serpentine Channel and Rheo-diecasting Process of A356 Aluminum Alloy [Dissertation], University of Science and Technology Beijing, 2011, p. 45.

[26] X.P. Sun, L. Shi, R.G. Guan, S.C. Wang, and W.J. Qi, Study progress and new trends of grain refinement in aluminum alloys, Non-Ferrous Min. Metall., 26(2010), No. 5, p. 32.

[27] W.X. Song, Metallography, Metallurgical Industry Press, Beijing, 2008, p. 231.

[28] E.P. Masuku, H. Möller, U.A. Curle, P.C. Pistorius, and W. $\mathrm{Li}$, Influence of surface liquid segregation on corrosion behavior of semi-solid metal high pressure die cast aluminum alloys, Trans. Nonferrous Met. Soc. China, 20(2010), Suppl. 3, p. 5837.

[29] Y.F. Wang, Solution Treatment of Vacuum High Pressure Die Cast Aluminum Alloy A380 [Dissertation], University of Windsor, Windsor, 2004, p. 34. 